\title{
ARTE EN LA ENCRUCIJADA. LA RECEPCIÓN DE LA OBRA DEL PINTOR GRIEGO DIMITRI PERDIKIDIS (1922-1989) EN ESPAÑA
}

\author{
Miguel Fernández Belmonte ${ }^{1}$ \\ Universidad Aristóteles de Salónica
}

\begin{abstract}
En el marco del arte contemporáneo de la segunda mitad del siglo XX, son fundamentales los mecanismos de asimilación y recepción de la obra de aquellos artistas que vivieron, de manera permanente o durante largos períodos de tiempo, como extranjeros en un país distinto al propio. Un caso de especial interés es el de los artistas griegos y en concreto el del pintor Dimitri Perdikidis (1922-1989) que vivió entre 1953 y 1985 en Madrid. El artículo se propone analizar algunos de los aspectos del proceso de integración de su obra en el contexto artístico español teniendo en cuenta su recepción por parte de la crítica.
\end{abstract}

Palabras clave: Perdikidis; pintura; Grecia; España; recepción crítica; siglo XX.

\section{ART AT THE CROSSROADS. THE RECEPTION OF THE WORK OF THE GREEK PAINTER DIMITRI PERDIKIDIS (1922-1989) IN SPAIN}

In the context of contemporary art of the second half of the $20^{\text {th }}$ century, the mechanisms of assimilation and reception of the work of the artists who lived permanently or for long periods abroad are essential. Of special interest is the case of Greek artists and specifically the painter Dimitri Perdikidis (1922-1989), who lived in Madrid from 1953 to 1985 . This article focuses on the analysis of some aspects of the process of integration of his work in the Spanish artistic context, taking into consideration its critical reception.

Key words: Perdikidis; painting; Greece; Spain; critical reception; $20^{\text {th }}$ century.

Cómo citar este artículo / Citation: Fernández Belmonte, Miguel (2017): “Arte en la encrucijada. La recepción de la obra del pintor griego Dimitri Perdikidis (1922-1989) en España”. En: Archivo Español de Arte, vol. 90, núm. 358, Madrid, pp. 171-182. doi: 10.3989/aearte.2017.11

Tras la guerra civil griega (1946-1949), fueron muchos los artistas griegos que decidieron marchar al extranjero. La mayoría fue a Francia debido a que "Gran parte de los jóvenes artistas, de los que la mayor parte había participado en la resistencia, aprovechó las becas que ofrecía el gobierno francés para instalarse en París (1945)"'2.

Entre los artistas que fueron a la capital francesa contamos, entre otros, a Paulos Dionisopoulos, Christos Karas, Chrissa Romanou, Constantinos Buzantios, Iason Molfesis, Yannis Gaitis, Danil Panagopoulos y Constantinos Xenakis. Otros decidieron ir a Roma, como es el caso de Yannis Kounelis que en 1959 fundó allí el grupo Sigma junto a Vlasis Kaniaris, Yannis Gaitis, Alekos Kontos y Constantinos Tsoclis.

\footnotetext{
1 miguel_77belmonte@yahoo.es / ORCID iD: http://orcid.org/0000-0001-5658-2538.

2 Spiteris, 1983: 17
} 


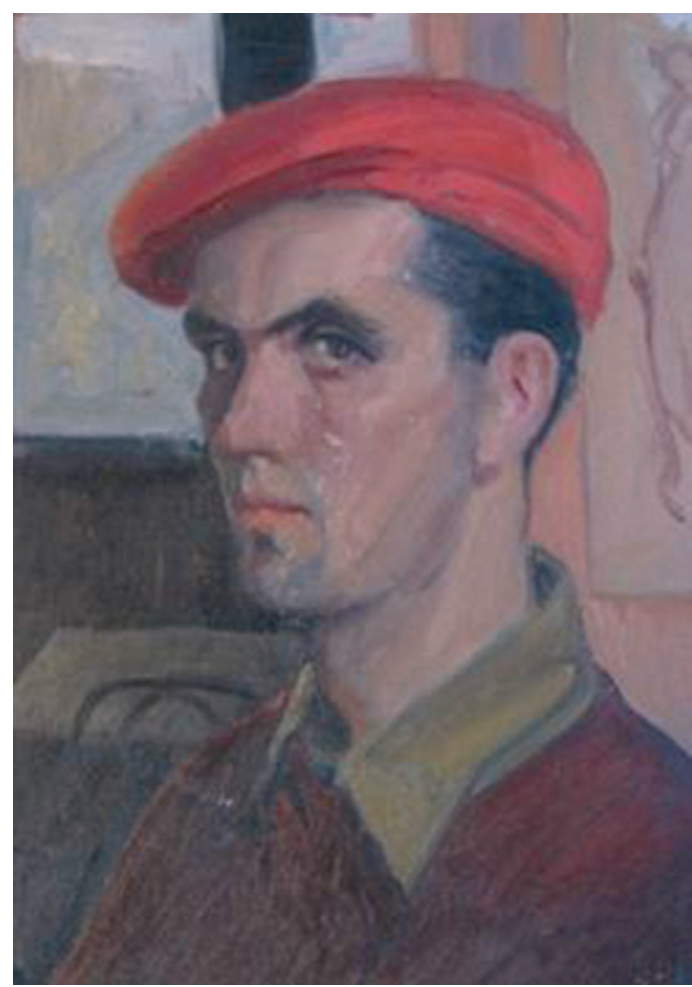

Fig. 1. Autorretrato, c. 1945, óleo sobre lienzo, $29 \times 21 \mathrm{~cm}$., colección privada.

Nacido en Neo Faliro, hijo de una familia bien situada, pero en serias dificultades desde la ocupación alemana de 1941, Dimitri Perdikidis se formó en la Escuela de Bellas Artes de Atenas entre 1943 y 1950 en las clases de profesores como el pintor Andreas Georguiadis, de quien recibió de manera indirecta la influencia de la pintura francesa, de Cèzanne y Matisse $^{3}$. En este período, 1943-1950, realizó además de diferentes copias del natural y apuntes, retratos de vecinos, amigos, y paisajes. Se trata de una pintura que explota los recursos del color, creando sombras coloreadas, contrastes cromáticos y que utiliza los diferentes grosores de la línea para crear profundidad (fig. 1).

Perdikidis participó en la resistencia griega contra los alemanes y durante un período de tiempo, probablemente a finales de 1944 durante la represión inglesa acaecida en la capital griega tras la liberación de Atenas ${ }^{4}$, fue apresado y conducido al campo de concentración de El Daba en Egipto 5 .

Gracias a la mediación del cura católico Irineo Tipaldo, empleado en la Embajada de España en Atenas, Perdikidis consiguió una beca del Ministerio de Asuntos Exteriores español para enriquecer su formación en la Escuela de Bellas Artes de San Fernando en Madrid entre 1953 y 1955.

En cuanto a esa decisión de Perdikidis de marchar a Madrid, parece tratarse de una decisión impulsada por el deseo de irse de Grecia debido a las dificultades económicas y de aprovechar la oportunidad inmediata de obtener una beca del Ministerio de Asuntos Exteriores español, más que de un acto largamente premeditado y programado. Además, tal vez tuviera el deseo de dejar atrás las vivencias del período de la dominación alemana y la guerra civil griega.

Se trata del primer caso conocido del siglo XX de un artista griego que vivió y desarrolló su trayectoria artística en España, seguido de cerca por el artista grabador Dimitri Papagueorguiu que llegó en 1954 a Madrid tras sus estudios en la Escuela de Bellas Artes de Atenas con el maestro grabador Yannis Kefalinós ${ }^{6}$. También por un breve período de tiempo se instaló en Madrid el pintor Theodoros Márkelos.

Los casos mencionados, si bien se incluyen en el fenómeno más amplio de la emigración al extranjero de artistas griegos en la década de los 50, no dejan de ser excepcionales dado que eligieron como destino un país que se encontraba bajo un régimen dictatorial.

Al considerar la actividad artística de Perdikidis en España destaca su participación en la Bienal hispanoamericana de 1955 en Barcelona, en la Bienal de Sao Paulo en 1961, en la Feria Internacional de Nueva York en 1962 y en la Bienal de Venecia en dos ocasiones (1964 y 1966)

\footnotetext{
3 Fernández Belmonte, 2014: 40.

${ }^{4}$ Durante Diciembre de 1944 se produjeron en el centro de Atenas duros enfrentamientos entre los comunistas del Ejército Popular de Liberación Nacional (ELAS) y el ejército británico.

5 Fernández Belmonte, 2016: 30-31.

6 Papagueorguiu García, 2003: 11.

7 Kotzamani, 2001: 284.
} 
además de participar en varias exposiciones de arte contemporáneo español en el extranjero durante la década de los 60 (en Bruselas, Helsinki, Casablanca, Rabat, Tetuán, Berlín, Bonn y Múnich).

En la prensa española, desde 1954 hasta 1988, se publicaron más de 200 artículos sobre las exposiciones y la obra de D. Perdikidis ${ }^{8}$, entre los que destacan los de importantes críticos de arte como José de Castro Arines, Carlos Areán, José María Moreno Galván, Manuel Sánchez Camargo, Cirilo Popovici, Figuerola Ferretti, Manuel Campoy y José Hierro en $A B C$, Hoja de Lunes, Arriba, Pueblo, Ya, Informaciones, El Alcázar y la revista Goya.

Teniendo en cuenta la participación de Perdikidis en eventos internacionales junto a artistas españoles, sus exposiciones individuales en España (realizó 18 exposiciones individuales entre 1954 y 1980 en Cuenca, Madrid, Bilbao y Barcelona) y la buena acogida crítica de su obra, cabría preguntarse cómo fue posible esa integración de un artista extranjero en la escena artística española durante la dictadura franquista.

Durante los años 50 la dictadura siguió, también los encarcelamientos y ejecuciones, pero bajo Franco, los gobiernos cambiaban. Los tecnócratas entraban en los diferentes organismos, en un marco de incipiente desarrollo económico, auspiciado por el deseo de recuperar las relaciones internacionales, sobre todo con Estados Unidos, en el nuevo marco de la Guerra Fría9.

En Madrid, Perdikidis se interesó por la obra de El Greco (fig. 2-3), por la obra de Diego Velázquez, como demuestra su copia del retrato de Mariana de Austria (fig. 4), y pudo conocer de primera mano la obra de Francisco de Goya. También se interesó por la pintura de José Gutiérrez Solana cuya influencia se evidencia en algunos de sus dibujos (fig. 5).

En una entrevista en 1956 afirmaba: "La pintura española siempre me pareció extremadamente humana y expresiva. Y como yo había nacido casi a la sombra del Partenón, en un clima de clasicismo y serenidad, sentí la necesidad de venir aquí"

Diez años más tarde añadía el contexto griego como una de las razones que le impulsaron a venir a España. "Yo vine de Grecia a España a raíz de nuestra guerra civil, en un momento en que allí los artistas no encontrábamos clima propicio. En Grecia, por otra parte, no hay Museos de pintura, y las Exposiciones de pintores extranjeros eran escasísimas. El Greco se vino a España en circunstancias parecidas: cuando su isla estaba en poder de los turcos"11.

Tras la dictadura de Franco, volvió a declarar su admiración por el arte español. "He vivido todos estos años, y seguiré viviendo en España, porque este país tiene una tradición viva, una historia de siglos que continúa, mientras Franco nunca fue más que un paréntesis. Y lo que vale subrayar aquí es la competencia del maravilloso pueblo español, su talento y su creatividad, que son armas de las más eficaces para cada tipo de adversidad. Recordemos a Goya en su 'período negro', al excelente Solana, tan poco conocido en Grecia, incluso al mismo Picasso, que en la época del Guernica era director del Prado. Por no hablar de los más jóvenes, de toda esta extraordinaria generación de Tàpies, Genovés, Canogar y tantos otros artistas valiosos" $" 12$.

Una vez en Madrid, Perdikidis se interesó también por la obra de Pablo Picasso y Joan Miró, como se puede deducir de algunas de sus cartas al pintor Vasilis Solidakis ${ }^{13}$ y de sus dibujos y obras, en especial alrededor de 1958 (fig. 6).

Entre 1953 y 1958 el pintor griego recibió diferentes estímulos e influencias que podríamos definir como una fase de asimilación y experimentación durante la que realizó varias exposiciones en Cuenca y una antológica en el Museo de Arte Contemporáneo en Madrid en 1957. Un elemento a destacar es que esas influencias provenían de artistas, como Solana y Picasso, que constituían un estímulo también para la obra de muchos artistas españoles de entonces.

\footnotetext{
8 Fernández Belmonte, 2016: 282-284.

9 Jover Zamora/Gómez-Ferrer/Fusi Aizpúrua, 2001: 713.

10 Alfaro, 1958.

11 Prados de la Plaza, 1966.

12 Pilijos, 1977.

${ }^{13}$ Fernández Belmonte, 2016: 289-292.
} 


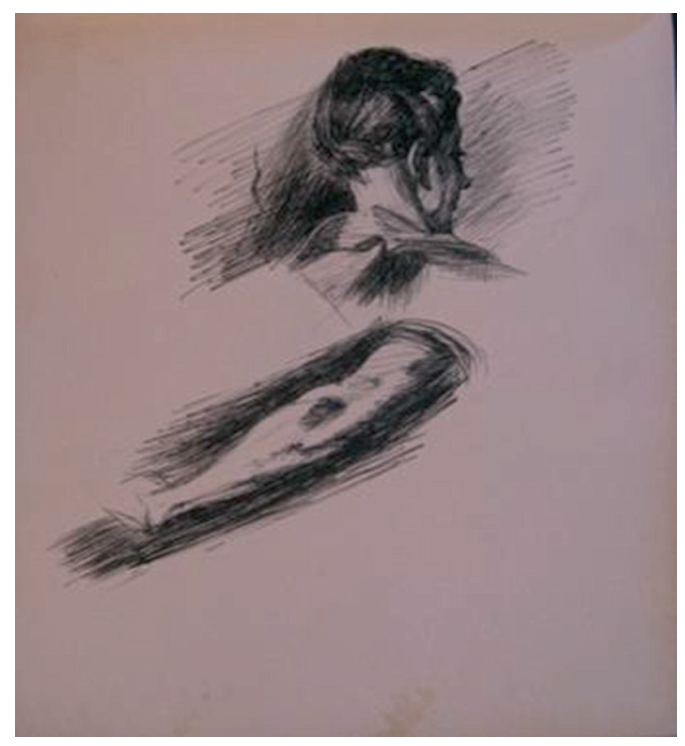

Fig. 2. Dibujo, lápiz sobre papel, $23 \times 19,5$ cm., colección privada.

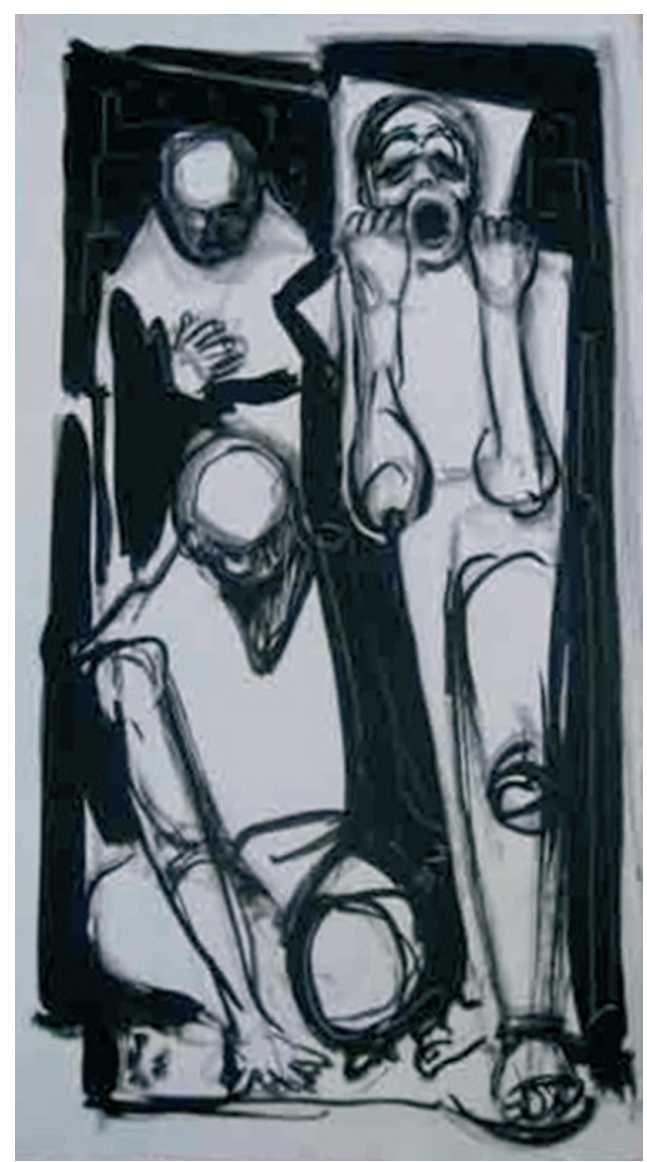

Fig. 4. Dibujo, tinta sobre papel, $32 \times 18 \mathrm{~cm}$, colección privada.

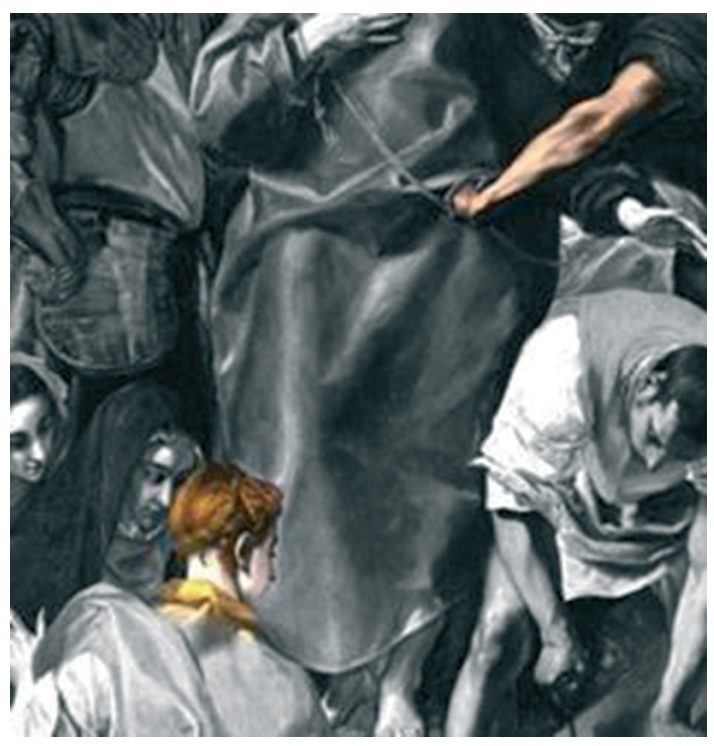

Fig. 3. Detalle: Doménikos Theotokopoulos, "El Greco": El Expolio, c. 1578, óleo sobre lienzo, Catedral de Toledo.

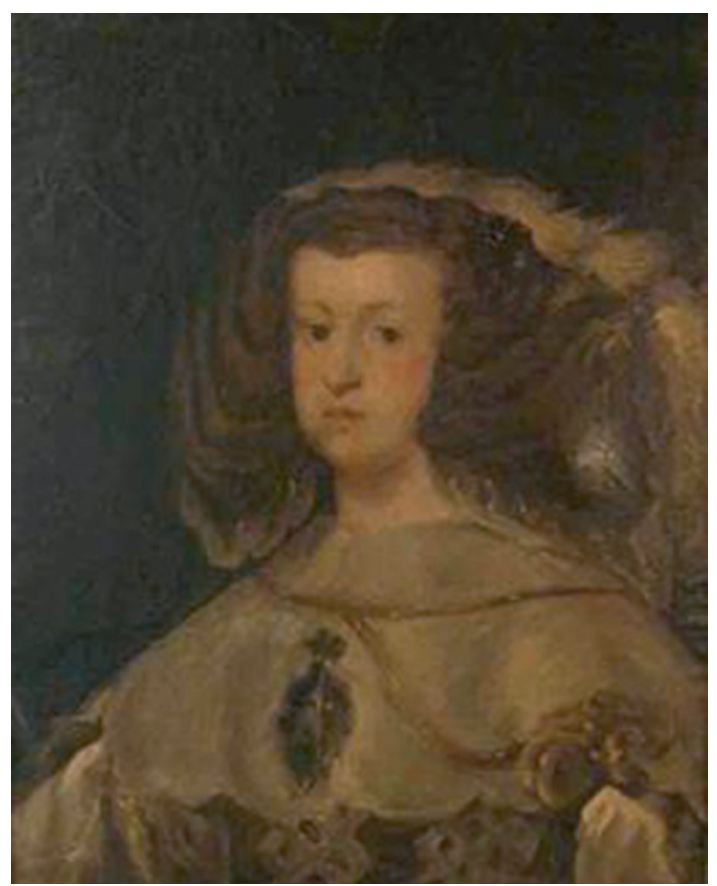

Fig. 5. Óleo sobre lienzo, 78,5 × 65,5 cm., colección privada, copia de Diego Velázquez: Retrato de Mariana de Austria, óleo sobre lienzo, c. 1656, colección Thyssen-Bornesmiza, MNAC, Barcelona. 
Fig. 6. Óleo sobre lienzo, 1958,

$61 \times 81 \mathrm{~cm}$, Donación

Leonidas y Denise

Perdikidis, Fundación

Aikaterini Laskaridis,

Atenas.

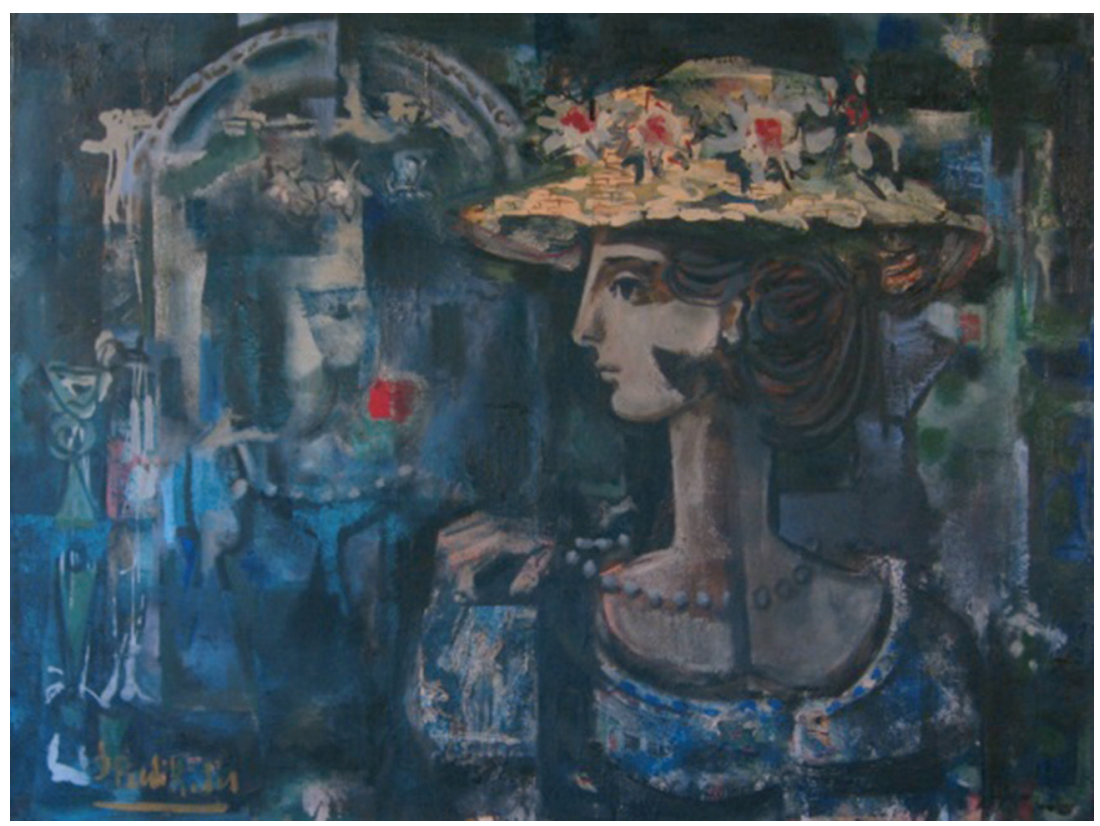

Desde el Congreso de Santander de 1953 hasta los éxitos de los pintores abstractos españoles en 1958 y el respaldo institucional a esos artistas de vanguardia a través de la figura de Luis González Robles en los eventos internacionales, la abstracción se fue consolidando como alternativa frente a otras opciones plásticas como el surrealismo o el expresionismo ${ }^{14}$. Artistas como los miembros del grupo El Paso y otros como Modesto Cuixart, Joan Ponç y Antoni Tàpies, realizaron una obra abstracta dotada de una originalidad propia, aunque no ajena a la influencia internacional del expresionismo abstracto americano y sobre todo del informalismo parisino.

Perdikidis tuvo ocasión de conocer a varios de ellos, como Antonio Saura y Manolo Millares y fue asimilando de manera gradual la catarsis que suponía adentrarse por el camino de la abstracción. Hacia 1958 los fondos de las pinturas de Perdikidis se vuelven más abstractos y apenas se reconocen los elementos figurativos, mientras que aumenta la importancia de las diferentes calidades, visuales y táctiles, de la superficie pictórica.

Es patente en esos años, sobre todo a partir de 1960, la influencia de los abstractos españoles, por ejemplo de Antoni Tàpies en obras como las que expuso en la exposición individual del Ateneo de Madrid en 1961 (fig. 7), pero Perdikidis al mismo tiempo, fue desarrollando su propio vocabulario expresivo, su propia propuesta artística, distanciándose de una mera recepción o imitación pasiva de la obra de otros creadores.

Es entonces cuando aparecen letras y signos que son un eco de un pasado lejano, que se plantean como una reinterpretación de lo griego en una clave humana y contemporánea. Los motivos decorativos geométricos, las volutas, las espirales, los círculos de las cerámicas clásicas, aparecen excavados, en relieve, sobre la capa pictórica, como recuerdos dotados de una carga simbólica.

"Más tarde, en 1960 comienzo mis búsquedas sobre la materia y las memorias griegas. No me refiero a las hagiografías, sino a la Grecia de Heráclito, a la Grecia del orden, del pensamiento y de la investigación. Tenía conmigo los libros de Christian Zervos que se refieren a la cerá-

14 Díaz Sánchez/Llorente Hernández, 2004: 60-64. 


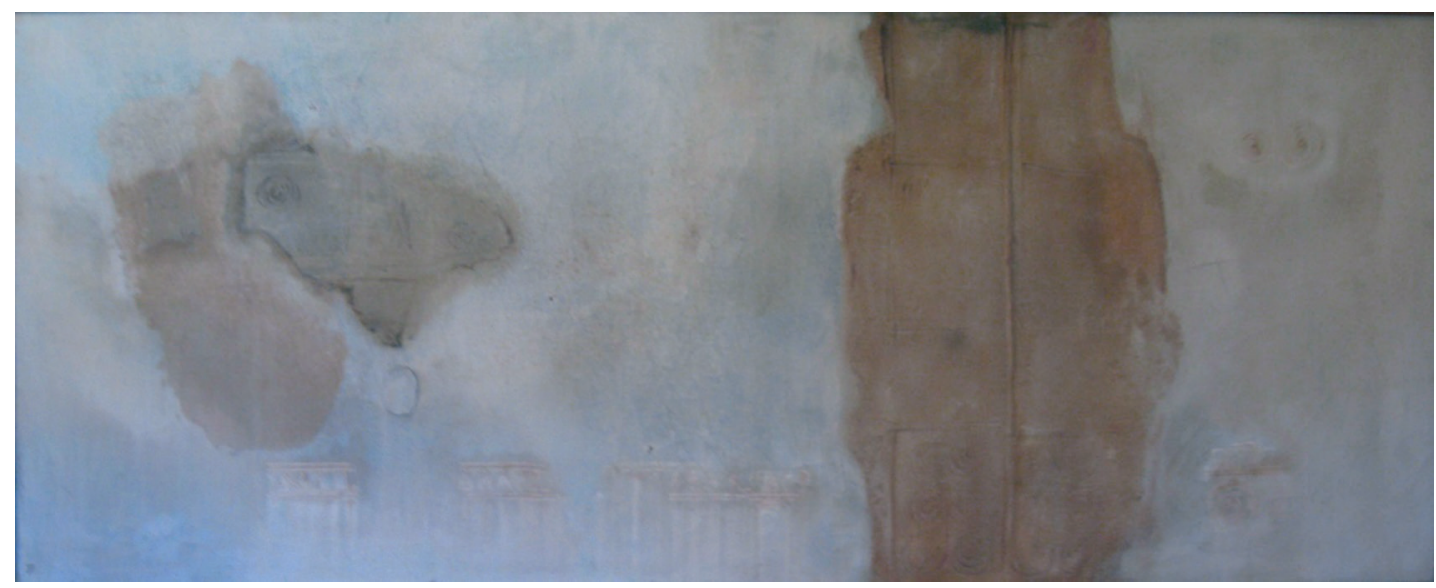

Fig. 7. Técnica mixta sobre madera, 1961, $83 \times 201,5 \mathrm{~cm}$, Donación Leonidas y Denise Perdikidis, Fundación Aikaterini Laskaridis, Atenas.

mica cicládica y cretense. Éstos fueron el punto de partida de mi trabajo abstracto que presento en 1960 en el Ateneo de Madrid y me dan el premio de la crítica de arte de España"15.

Desde 1959 hasta 1967 Perdikidis produjo una obra abstracta con la que se constituyó como miembro activo de la escena artística española (fig. 8), como corroboran el premio de la crítica del Ateneo de Madrid y la Medalla de Plata de la galería Kasper de Lausanne, ambos recibidos en 1961, por su obra Orfeo.

Perdikidis a través de su obra abstracta vuelve a Grecia, pero no de una manera nostálgica o con la intención de definir la identidad griega en general (intencionalidad que encontramos en muchos pintores griegos, sobre todo del período de entreguerras como Yannis Tsarouchis, Yannis Moralis, Fotis Kontoglou y Nikos Engonopoulos, entre otros ${ }^{16}$ ). Se trata más bien de una mirada contemporánea, individual y personal sobre la propia identidad. Perdikidis no persigue definir lo griego en abstracto, sino que, de manera más concreta, persigue expresar el sentido de lo griego en su propio arte.

Carlos Areán hizo referencia a la voz griega presente en las obras de Perdikidis: “[...] una voz domina el griego en sus cuatro dialectos: perfecta, sonora, limpia, bellamente estructurada en su clásica, vieja, mediterránea musicalidad. Perdikidis es un griego que cavila y sueña a exigencias de la propia calentura patria. Aquí está Minos y su laberíntica arquitectura; la tierra micénica, el aire de los heráclidas arcaicos, la luz y el rayo y la piedra y la tierra que va como realidad inolvidable en el alma del hombre"17.

Para J. E. Cirlot sus obras estaban llenas de calidades de la cerámica, como hallazgos arqueológicos, símbolos del tiempo histórico ${ }^{18}$. También José de Castro Arines, rastreó en su pintura, la Grecia eterna ${ }^{19}$, pero también las sucesivas Grecias históricas: "Pero tampoco encasillo yo a nuestro pintor en ningún momento histórico definido en el tiempo; un poco lo sitúo en el tiempo micénico, otro en el tiempo de Escopas, otro en el de la brillante orfebrería del helenismo bizantino. El corazón se abre en Perdikidis como una joya resplandeciente"20.

\footnotetext{
15 Theofilis, 1985?: 49.

16 Fernández Belmonte, 2011: 249-251.

17 Areán, 1961. Archivo M. Kotzamani, Atenas.

18 Cirlot, 1962. Archivo de la familia Perdikidis, Atenas.

19 Castro Arines, 1966. Archivo M. Kotzamani, Atenas.

20 Castro Arines, 1967. Archivo M. Kotzamani, Atenas.
} 


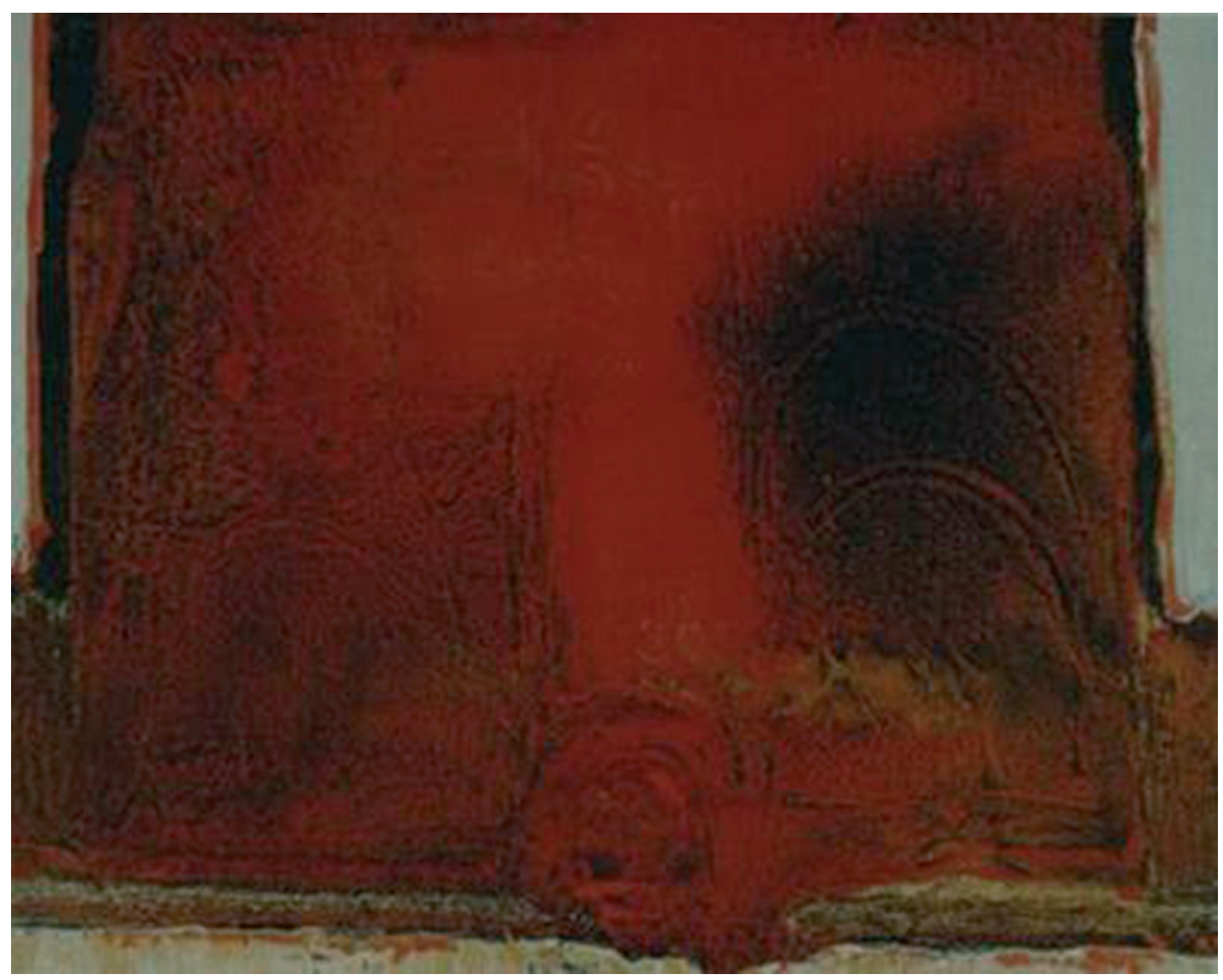

Fig. 8. Técnica mixta sobre madera, 1962, $40 \times 50 \mathrm{~cm}$, Donación Leonidas y Denise Perdikidis, Fundación Aikaterini Laskaridis, Atenas.

Críticos como A. M. Campoy subrayaron como claves en la pintura abstracta de Perdikidis por un lado el equilibrio, la armonía y la medida de lo apolíneo, y por otra el componente dionisiaco de la pasión y lo trágico.

J. R. Alfaro escribió: "Si bien Perdikidis se dejó influir, como muy acertadamente señala José Ayllón durante los primeros años que residió en nuestro país, por la pintura española, su regreso a Grecia y su reencuentro con la cultura helénica marcó en él una nueva etapa que al surgir por un proceso mental se formulaba rigurosamente como una decantación del espíritu, alcanzado por el puro intelecto, en contraposición con su época anterior, mucho más temperamental" 21.

En A. M. Campoy, J. de Castro Arines y otros críticos tenemos una referencia constante a la identidad griega de la pintura de Perdikidis muchas veces opuesta a un componente más netamente trágico y pasional. Esta concepción podría relacionarse con la teoría del arte de Heinrich Wöfflin en la que las obras de arte se definen en base a parejas de opuestos que a su vez definen los varios estilos y así los períodos clásicos de la armonía se alternan con los barrocos de la violencia y lo atmosférico ${ }^{22}$. Pero en el caso de Perdikidis, ese tipo de análisis reviste de una importancia especial en el contexto de la recepción crítica de la pintura abstracta en España.

21 Alfaro, 1967. Archivo M. Kotzamani, Atenas.

22 Bozal, 2002: 264-266. 
Más que un paradigma traído desde el extranjero o una interpretación y asimilación de la obra de diversos artistas de las grandes metrópolis, como París y Nueva York, la abstracción pudo abrirse camino en el contexto de la dictadura desde su identificación como un arte de su tiempo, espiritual, apolítico y dotado de un carácter claramente español ${ }^{23}$. Las obras abstractas, por ejemplo, de Antonio Saura y Rafael Canogar, tenían su referente en los maestros de la pintura española, ante todo en Goya, siendo ejemplo de una abstracción dotada de la idiosincrasia española y con profundas raíces históricas.

Ante la obra de un extranjero venido de Grecia, el tema de la identidad nacional de la pintura abstracta adquirió en buena parte de la crítica española la dimensión añadida de la comparación. Antes que con Tàpies, con Vedova o con Millares, la obra de Perdikidis se interpretó desde su herencia nacional, desde los elementos que la identificaban como griega, es decir la armonía, el clasicismo y la medida, y al mismo tiempo, como receptora del diacrónico, apasionado y trágico espíritu español.

El respaldo institucional que recibió Perdikidis a través de su intensa participación en exposiciones de arte contemporáneo español en el extranjero y bienales y la buena acogida de su obra por parte de la crítica española pueden explicarse en parte dentro de ese marco de interpretación en clave nacional del arte abstracto.

Es decir, que la obra de Perdikidis tuvo esa recepción porque pudo constituirse ante los ojos de la crítica como ejemplo de los rasgos nacionales del arte; de ahí ese énfasis reiterado en la separación de lo griego y lo español en los análisis de su obra en los críticos españoles, en vez de considerar su pintura como un todo, dotado de unidad y coherencia propias.

El artista pasó a ser considerado como un mero transmisor de unos valores inmutables a través de la historia, como la serenidad y la medida de la Grecia de Pericles, como si entre medias, hasta la época contemporánea, no hubieran transcurrido más de dos milenios de cambios y profundas transformaciones. De la misma manera, su relación con lo español se limitó muchas veces desde la crítica a la capacidad del pintor de reflejar los valores "inmutables" de la pintura española, el sentimiento trágico, lo pasional, lo dionisiaco.

A partir de 1967, como en el caso, pocos años antes, de otros artistas como Rafael Canogar y Luis Genovés, observamos un cambio en la pintura de Perdikidis hacia un arte entendido como un diálogo, como testigo de su época y como compromiso.

Ese cambio también fue señalado por la crítica, que siguió apreciando la belleza y armonía de su arte, aunque ahora dotada de mayor conciencia política y social; José Hierro apuntó: "Afloran aquí en todo su goce pictórico las voces del alma de este griego, español de adopción, uno más con nosotros por la energía, vitalidad, seguridad, firmeza de sus querencias íntimas, arrebatadas siempre, tan perfecta y armoniosamente descritas" 24 .

Es un proceso que se dio de manera gradual y se completó en 1967, el mismo año que en Grecia se instauró la dictadura de los coroneles hasta 1974. Los recortes de la prensa, los rostros de la hambruna en África, la guerra de Vietnam, la dictadura de Pinochet, el asesinato de Che Guevara o la inmolación del monje Thich Quang Duc (fig. 9-10) hacen su aparición en una pintura de tono reivindicativo caracterizada por los motivos geométricos, la combinación de técnicas (uso del aerosol, la serigrafía, etc.), la repetición y también por la distancia que marca el artista en lo formal respecto al sujeto, a la manera de Bertolt Brecht en el teatro.

Su pintura fue valorada entonces por la crítica española respecto a su obra anterior y también desde la consideración de sus obras como símbolos que transmiten el lenguaje de la actualidad. La despersonalización, la neutralidad y el uso de imágenes en un nuevo marco de significado fueron señaladas por críticos como S. Marchán Fiz como las características más destacables de su obra de este período ${ }^{25}$.

Al mismo tiempo, críticos como J. M. Moreno Galván, siguieron realizando una interpretación de su pintura en base a los rasgos identificativos nacionales. El contenido de las obras de

23 Díaz Sánchez, 2013: 17-20, 63.

${ }^{24}$ Hierro, 1971. Archivo Tonis Spiteris, Fundación Telogleion, Salónica.

25 Marchán Fiz, 1970: 70-75. 

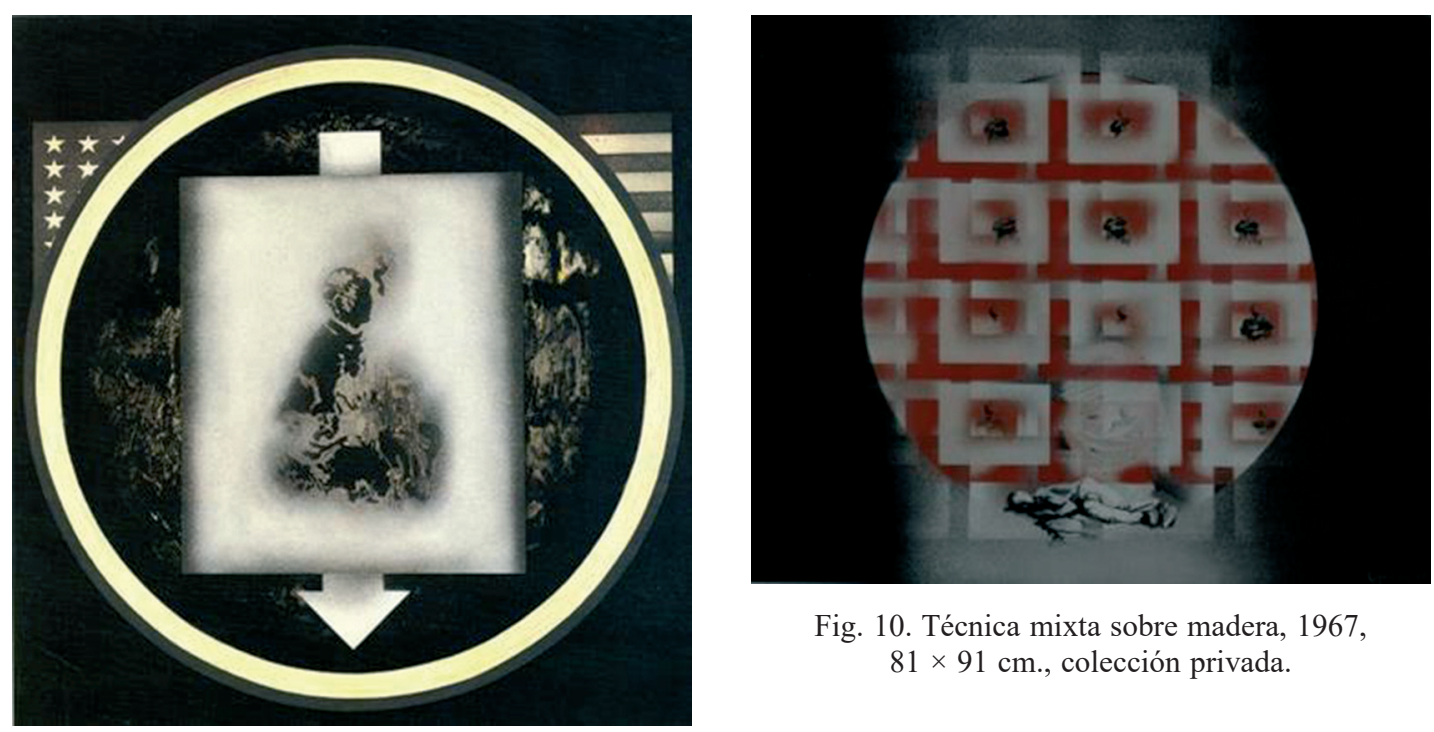

Fig. 10. Técnica mixta sobre madera, 1967, $81 \times 91 \mathrm{~cm}$., colección privada.

Fig. 9. Técnica mixta sobre madera, 1972, $160 \times 150 \mathrm{~cm}$., colección privada.

Perdikidis, que remitía a la realidad contemporánea y sus formas de comunicación, fue considerado por Moreno Galván como una búsqueda del realismo, característica señalada por otra parte por el crítico como elemento esencial de la tradición pictórica española.

Durante este período, alrededor de 1967, en el que la obra de Perdikidis adquirió un contenido más político y social que no encajaba con la imagen que el régimen franquista deseaba promover, y tampoco tenía cabida en el marco de la dictadura de los coroneles en Grecia, la crítica señaló ese cambio de orientación y a nivel institucional no encontró ya ningún apoyo (no volvió a participar en eventos internacionales de importancia ni a representar el arte contemporáneo español en el extranjero).

Tras la dictadura franquista, Perdikidis realizó numerosas exposiciones individuales y participó en la exposición Panorama 78 del Museo de Arte Contemporáneo en Madrid en 1978. Además, colaboró con los artistas Anzo (Almohacid José Iranzo), Francisco Sobrino, Fernando Somoza, Valencia, José Luis Verdes, Ángel Orcajo, Alberto Datas y Urbina en una serie de grabados bajo la dirección de Venancio Sánchez Marín en 1979.

En 1981, en el mismo año que la vuelta del Guernica simbolizaba el inicio de una renovación institucional en el ámbito del arte contemporáneo, Perdikidis se encontraba encerrado en sí mismo, casi sin salir de su casa tras la muerte de su mujer Eleni Olivieri. No realizó exposiciones individuales ni colectivas, excepto su participación en la exposición itinerante Artistas en homenaje al Greco en las salas de la Caja Postal de España entre 1982 y 1983.

Es un período en el que podríamos señalar que se interrumpe su implicación activa en el contexto artístico español, distanciamiento acentuado por su marcha a Grecia en 1985, a Atenas, donde vivió hasta su muerte en 1989.

Allí produjo una obra en la que predomina la abstracción geométrica (fig. 11), pero en la que asoman recuerdos y miradas de épocas anteriores, como el collage de artículos de la prensa, las pinceladas dotadas de mayor expresividad y soltura o el interés por el tratamiento de las diferentes texturas de la superficie pictórica. Sin embargo esas obras no establecen ninguna comunicación con las de otros artistas que en España habían trabajado en ese sentido como Palazuelo, Ibarrola o Sempere. Su obra no volverá a mencionarse hasta la exposición colectiva Madrid el arte de los 60 en 1990. 


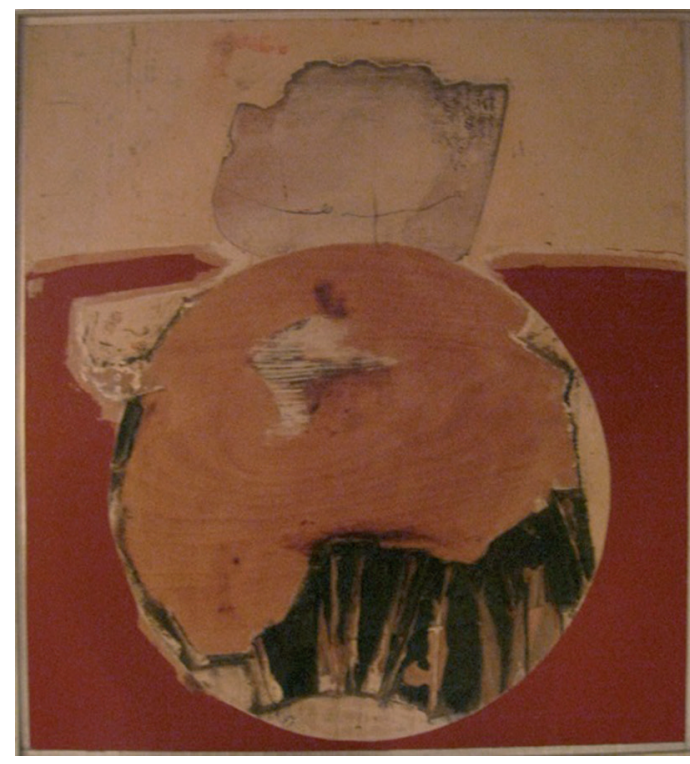

Fig. 11. Armonía III, 1963-1985, técnica mixta sobre madera, 104,5 × $95 \mathrm{~cm}$, colección privada.

Al considerar la obra de Dimitri Perdikidis, además de su contribución activa a la escena artística española sobre todo durante los años 60 y 70 y el propio valor intrínseco de sus pinturas y dibujos, es necesario añadir otro elemento más. Nos referimos a su papel de puente, de nexo a varios niveles, entre Grecia y España.

Durante la mayor parte de la segunda mitad del siglo XX, excepto la participación en bienales y otros eventos internacionales y la residencia de D. Papagueorguiu y Perdikidis en Madrid (y por un breve período de Theodoros Márkelos), son muy escasos los puntos de encuentro entre los artistas de ambos países, a pesar de que en Grecia se realizaron exposiciones sobre el arte español y los artistas abstractos españoles y que en España fue aumentando el interés por la Grecia contemporánea, sobre todo a través de la literatura ${ }^{26}$.

En el apartado de las exposiciones, podemos señalar la exposición de las obras de la participación española en la Bienal de Alejandría de 1955 con comisariado de Luis Gonzá-

lez Robles que viajó a Líbano, Siria, Irak, Turquía y Grecia. Un año después en la Asociación

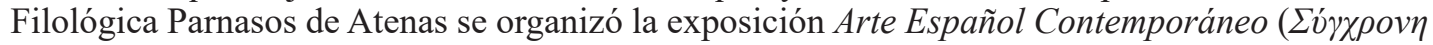

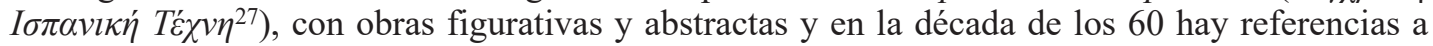
otras exposiciones de arte español ${ }^{28}$, como la organizada en 1962 sobre los grabados y dibujos de Picasso $^{29}$.

En marzo de 1967 en la galería Astor se realizó la exposición Spanish Art Now con obras, entre otros artistas, de R. Canogar ${ }^{30}$ y algunos años más tarde en 1971 en la misma galería se

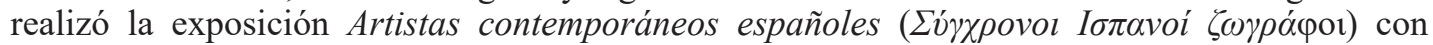
obras de Tàpies, Millares, Canogar, y Suárez, entre otros ${ }^{31}$. En 1983 la Pinacoteca Nacional or-

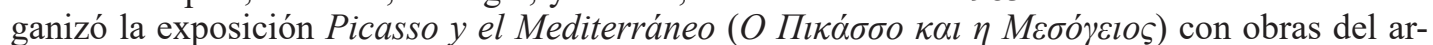
tista inspiradas en la antigüedad heleno-romana, los mitos griegos y la cultura mediterránea.

En septiembre de 1988, en el Teatro Municipal del Pireo, se realizó la exposición Grabado

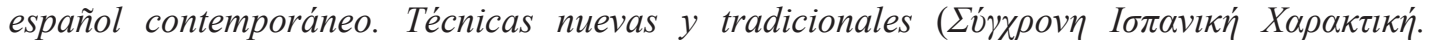

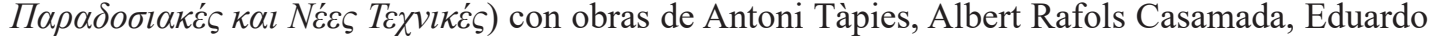
Chillida, Antonio Lorenzo, Josep Guinovart, Joan Ponç, Manuel H. Mompó, Lucio Muñoz, Antonio Saura, Jorge Castillo, Alfonso Bonifacio, Luis Pérez Vicente, Luis Gordillo, Esperanza Nuere, Alfredo Alcaín, Rafael Solbes, Manuel Valdés, Joaquín Capa, Jordi Teixidor, Mari Puri Herrero, Óscar Manesi, Gerardo Aparicio, Fernando Almela, José Hernández, Rosa Biadiu, Manuel Menan, Albert Porta, Andrés Nagel, Roberto González Fernández, David Lechuga, Fernando Bellver y Elena del Rivero ${ }^{32}$.

26 Liontis, 1999: 1.

27 Bakaló, 1981: 134.

28 Op. Cit., 56-57.

29 Xydis, 1976.

30 "Exposiciones colectivas". En: www.rafaelcanogar.com [04-06-2015].

31 Scaltsá (2012): 128.

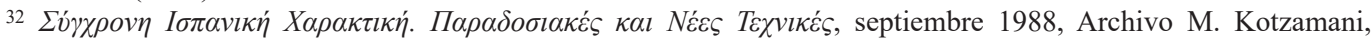
Atenas. 
A pesar de las exposiciones mencionadas, de algunas similitudes que podemos observar en el contexto del arte europeo contemporáneo entre la obra de varios artistas (Suárez-Kontopoulos, Tàpies-Lefakis, Kaniaris-Canogar, Kontós-Zóbel, Kesanlís-Millares, etc.) y algunas influencias, como la de la pintura del grupo El Paso en la obra de Tsoclis ${ }^{33}$, los artistas griegos, aunque admiraban la tradición pictórica española, no tenían muchas referencias sobre el arte español y su mirada se dirigía más bien hacia París. Los españoles, por otro lado, no conocían la obra de los artistas griegos y en todo caso se encontraron con aquellos griegos que ya vivían en el extranjero, principalmente en París y Roma ${ }^{34}$.

Por lo tanto, se podría señalar que la personalidad y la obra de Perdikidis facilitaron en cierta medida una mayor comunicación entre ambos contextos culturales, a través de sus exposiciones en Atenas ${ }^{35}$ y Madrid, sus declaraciones en la prensa sobre su tierra natal y sobre el arte español y los títulos de varias de sus obras expuestas en España que hacen referencia a la cultura griega (Teseo, Orfeo, Esopo, Centauro, Ícaro, etc.).

Además cabe tener en cuenta su implicación en la edición española de la Romiosini (Grecidad y otros poemas) de Yannis Ritsos en $1979^{36}$ con traducción de Eleni Perdikidi y su participación como miembro en la asociación cultural hispano-helena de Madrid.

Al intentar comprender la progresiva integración de la obra de Dimitri Perdikidis en el contexto artístico español, se han definido los años 1953-1958 como una fase de asimilación y experimentación, seguidos de una participación más activa en el mismo a través de su obra abstracta entre 1959 y 1967.

En esa segunda fase se ha señalado como elemento clave la adecuación de su obra abstracta a la interpretación de la misma por parte de la crítica española en términos nacionales. Una obra que la crítica planteó como griega y española, al mismo tiempo serena, equilibrada, trágica y pasional. Esa buena acogida crítica funcionó en paralelo con un respaldo a nivel institucional que permitió la participación de Perdikidis en eventos internacionales representando al arte contemporáneo español entre 1961 y 1967.

A partir de 1967 hasta 1981 la pintura de Perdikidis se inscribe en el realismo crítico y se caracteriza por su deseo de reflejar y denunciar los conflictos y desafíos contemporáneos (las guerras, la soledad, la injusticia, la deshumanización de la sociedad), con especial atención hacia Grecia.

En ese sentido, su obra tuvo mayor presencia como parte del conjunto de expresiones del arte griego que entonces protestaba contra la dictadura de los coroneles (Kokkinidis, Benetoulias, Psixopaidis ${ }^{37}$, etc.), que en el contexto artístico español en el que ya no participó en eventos internacionales de relevancia (tan solo hay constancia de su participación en 1969 en la II Bienal Internacional del deporte en las Bellas Artes en Madrid y en 1976 en el $1 .^{\circ}$ Certamen Internacional de artes plásticas en el Museo de Arte Moderno de Lanzarote).

Tras la muerte de su mujer Eleni en 1981 se evidenció el distanciamiento de Perdikidis respecto al contexto artístico español con su giro hacia una abstracción geométrica con un carácter marcadamente introspectivo y con su marcha a Atenas en 1985.

Podría citarse a Dimitri Perdikidis como un artista con dos patrias, pero en realidad su obra es única y coherente y sólo puede interpretarse de manera más completa desde la consideración del arte contemporáneo como una red dinámica, sin compartimentos estancos. Se trata de una obra con la que su creador buscó ampliar sus posibilidades creativas y mediante la que pretendió establecer un diálogo con la sociedad entendida en su sentido más universal, frente a la violencia y la desigualdad.

33 Sarakatsianoú, 2004: 119.

34 Sólo a partir de los años 60 y 70 se registra un interés de los griegos por España y un consiguiente aumento de los casos de residencia permanente (principalmente por motivos sociales y económicos). Jasiotis, 1999: 15.

35 Un ejemplo indicativo podría ser la traducción al griego de un texto de José de Castro Arines para el catálogo de la exposición de Perdikidis en Atenas en 1963 en la sala de exposiciones del Hotel Hilton y a cuya inauguración acudió el Embajador de España en Atenas.

36 Ritsos, 1979.

37 Kotidis, 2011: 18. 
La obra de Dimitri Perdikidis, por lo tanto, no se constituye en base a esa citada doble identidad griega y española, a esos dos mundos culturales, sino, ante todo, se encuentra en el espacio de su intersección, como ejemplo notable de lo que podríamos entender por artista contemporáneo europeo del siglo XX.

\section{Agradecimientos}

Quisiera agradecer a la familia Perdikidis el acceso a su archivo, así como la utilización de imágenes de las obras de Dimitri Perdikidis. Así mismo, quisiera agradecer la colaboración de la Fundación Aikaterini Laskaridis y señalar el apoyo del Organismo Estatal de Becas de Grecia (IKY), de la Fundación A. G. Leventis y del Centro de Investigaciones de la Universidad Aristóteles de Salónica, en mi investigación sobre la obra de D. Perdikidis.

\section{BIBLIOGRAFÍA}

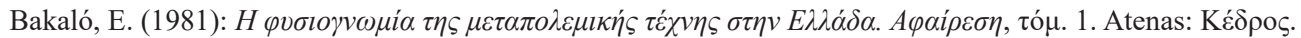

Bozal, V. (ed.) (2002): Historia de las ideas estéticas y de las teorías artísticas contemporáneas, vol. II. Madrid: A. Machado Libros.

Castro Arines, J. de (1966): "La obra antológica de Paulino Vicente y la pintura nueva de Dimitri Perdikidis". En: Diario de Barcelona.

Castro Arines, J. de (1967): "Las exposiciones". En: Informaciones.

Cirlot, J. E. (1962): "El diálogo en la obra de Perdikidis". En: Correo de las Artes, n. 35.

Díaz Sánchez, J. (2013): La idea de arte abstracto en la España de Franco, Madrid: Cátedra.

Díaz Sánchez, J.; Llorente Hernández, A. (2004): La crítica de arte en España (1939-1976), Madrid: Istmo.

Fernández Belmonte, M. (2011): "La modernidad sin centro. Pintores griegos de la primera mitad del siglo XX". En: Espacio, Tiempo y Forma, t.24. Madrid: UNED.

Fernández Belmonte, M. (2014): Dimitris Perdikidis. A painter of the diaspora, Atenas: Fundación A. Laskaridis.

Fernández Belmonte, M. (2016): La obra del artista Dimitris Perdikidis (1922-1989) y su recepción en España y Grecia, Tesis doctoral. Salónica: Universidad Aristóteles de Salónica.

Hierro, J. (1971): "Dimitri Perdikidis". En: Nuevo Diario. Madrid, El arte de los '60 (1990). Madrid: Editorial Comunidad de Madrid.

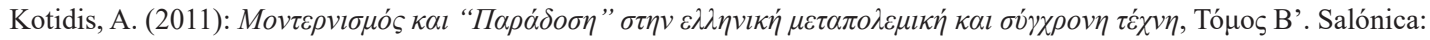
University Studio Press.

Kotzamani, M. (2001): Dimitri Perdikidis, catálogo de exposición. Herakleio: Editorial Ítanos-Fundación Ioanis F. Kostópulos.

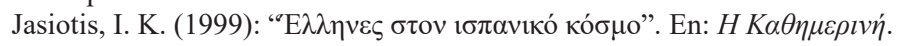

Jover Zamora, J. M.; ; Gómez-Ferrer, G.; Fusi Aizpúrua, J. P. (2001): España: sociedad, política y civilización (siglos $X I X-X X)$. Madrid: Debate.

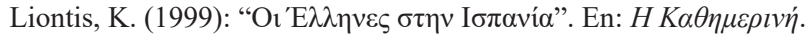

Marchán Fiz, S. (1970): Del arte objetual al arte del concepto. Madrid: Akal.

Papagueorguiu García, A. (2003): Vida y obra de Dimitri Papagueorguiu en las artes de la estampa, Tesis doctoral. Madrid: Universidad Complutense de Madrid, Madrid, 2003.

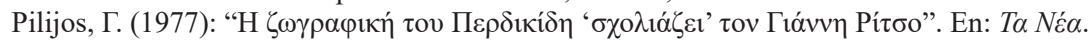

Prados de la Plaza, F. (1966): "Perdikidis pinta lo que siente en cada momento conforme a lo que le rodea y sucede". En: Arriba.

Ritsos, Y. (1979): Grecidad y otros poemas. Madrid: Visor.

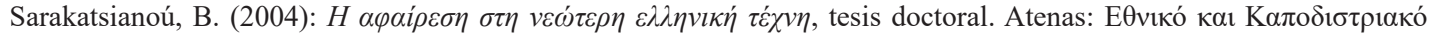

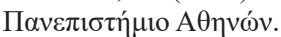

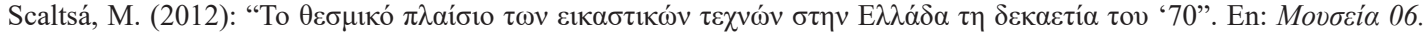

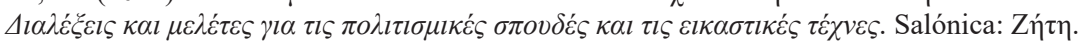

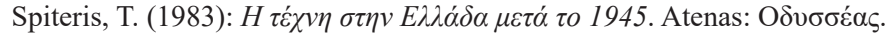

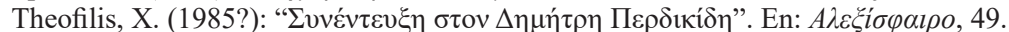

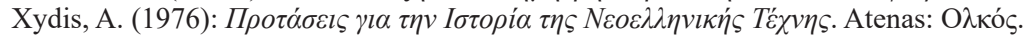

Fecha de recepción: 09-VI-2015

Fecha de aceptación: 27-XI-2015 